\title{
14-3-3 Proteins: A Family of Versatile Molecular Regulators
}

\author{
V. OBŠILOVÁ ${ }^{1}$, J. ŠILHAN ${ }^{1,2}$, E. BOUŘA ${ }^{1,2}$, J. TEISINGER $^{1}$, T. OBŠIL ${ }^{1,2}$ \\ ${ }^{1}$ Institute of Physiology, Academy of Sciences of the Czech Republic, v.v.i, Prague, ${ }^{2}$ Department of \\ Physical and Macromolecular Chemistry, Faculty of Science, Charles University, Prague, Czech \\ Republic
}

Received February 15, 2008

Accepted April 16, 2008

On-line May 13, 2008

\begin{abstract}
Summary
The 14-3-3 proteins are a family of acidic regulatory molecules found in all eukaryotes. 14-3-3 proteins function as molecular scaffolds by modulating the conformation of their binding partners. Through the functional modulation of a wide range of binding partners, 14-3-3 proteins are involved in many processes, including cell cycle regulation, metabolism control, apoptosis, and control of gene transcription. This minireview includes a short overview of 14-3-3 proteins and then focuses on their role in the regulation of two important binding partners: FOXO forkhead transcription factors and an enzyme tyrosine hydroxylase.
\end{abstract}

\section{Key words}

14-3-3 protein - Forkhead transcription factor FOXO4 - Tyrosine hydroxylase $\cdot$ Conformation

\section{Corresponding author}

T. Obšil, Department of Physical and Macromolecular Chemistry, Faculty of Science, Charles University, Hlavova 8, 12843 Prague 2, Czech Republic. E-mail: obsil@natur.cuni.cz

\section{Structure and function of 14-3-3 proteins}

The 14-3-3 proteins are a family of acidic regulatory proteins found in all eukaryotes $(\mathrm{Fu}$ et al. 2000). 14-3-3 proteins function as molecular scaffolds by modulating the conformation of their binding partners (Fu et al. 2000, Aitken 2006, Hermeking and Benzinger 2006). Through the functional modulation of a wide range of binding partners, 14-3-3 proteins are involved in many biologically important processes, including cell cycle regulation, metabolism control, apoptosis, and control of gene transcription (Fu et al. 2000, Aitken 2006,
Hermeking and Benzinger 2006). The unusual name of these proteins, "14-3-3", originates from their elution and migration pattern on two-dimensional DEAE-cellulose chromatography and starch gel electrophoresis (Moore and Perez 1967). Since the initial discovery of 14-3-3 proteins, members of this protein family have also been given other names, e.g. BAP-1, Bilardo, Exo1, Leonardo, Stratifin etc., when they have been rediscovered due to their involvement in many regulatory processes (Aitken 2006).

The 14-3-3 proteins are highly conserved over a wide range of eukaryotic species and many organisms express multiple isoforms (Fig. 1). While lower eukaryotes, e.g. yeast, contain only two 14-3-3 genes, higher eukaryotes possess up to 15 14-3-3 genes. For example, in mammals seven isoforms $(\beta, \varepsilon, \eta, \gamma, \tau, \zeta$ and $\sigma)$ have been identified to date. With exception of mammalian sigma isoform, all 14-3-3 proteins can form both homo- and heterodimers (sigma isoform preferentially forms homodimers) (Wilker et al. 2005). Initial structural studies confirmed a dimeric nature of 14-3-3 proteins and revealed that each monomer consists of nine antiparallel $\alpha$-helices (Liu et al. 1995, Xiao et al. 1995) (Figs 2A and 2B). A large $40 \AA$ wide deep channel located in the center of a cup-shaped 14-3-3 protein dimer contains two amphipathic grooves. Detailed analysis of interactions between 14-3-3 proteins and their targets and the use of an oriented peptide library screening approaches resulted in identification of two optimal 14-33 binding motifs: RSXpSXP and RX(Y/F)XpSXP (X denotes any amino acid residues except cysteine) (Muslin et al. 1996, Yaffe et al. 1997, Rittinger et al. 


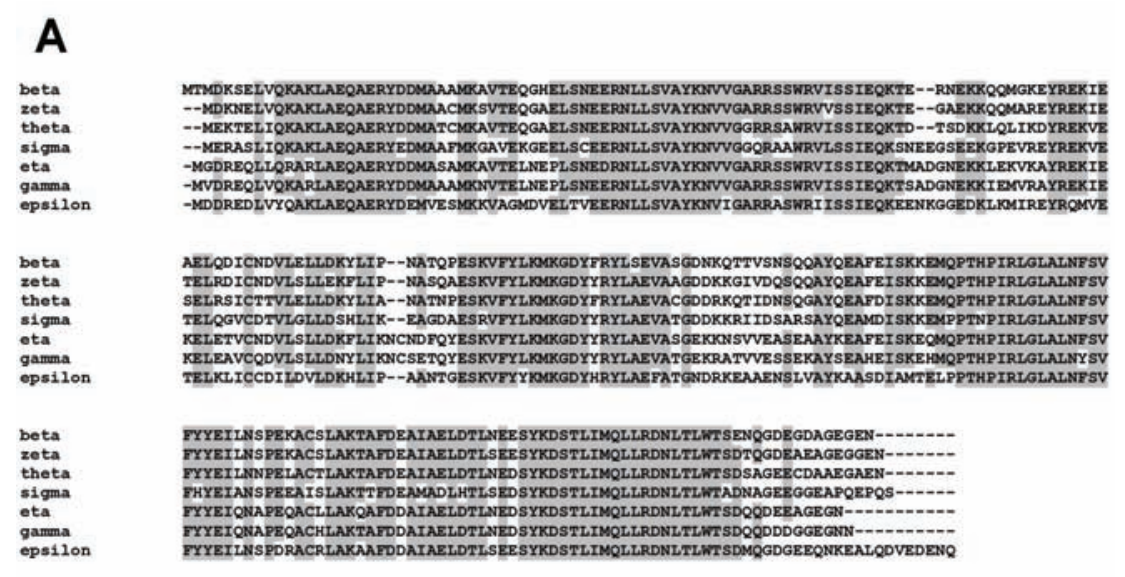

B

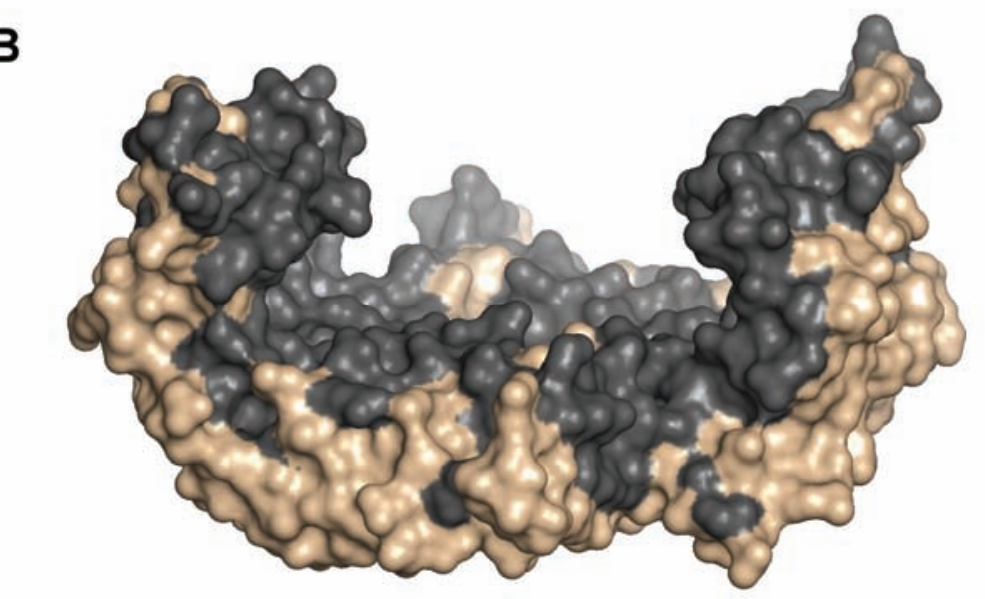

Fig. 1. Sequence conservation of 14-3-3 isoforms. (A) Sequence alignment of human 14-3-3 protein isoforms. Residues that are conserved at least in five sequences are shaded in gray. (B) Structure of human 143-3ל isoform (surface representation) shaded according the sequence conservation (Rittinger et al. 1999). Residues that are totally conserved among all human isoforms are shaded in dark gray.
1999). Crystal structures of phosphopeptide-bound 14-3-3 complexes demonstrated that $\mathrm{pS}$ (or pT)containing segments ( $\mathrm{pS}$ and $\mathrm{pT}$ denotes phosphoserine and phosphothreonine, respectively) are bound within amphipathic grooves at either edge of the central channel of the 14-3-3 dimer and adopt an extended main chain conformation (Fig. 2) (Yaffe et al. 1997, Petosa et al. 1998, Rittinger et al. 1999). The phosphate group of phosphoserine (or phosphothreonine) is coordinated by salt bridges to the side chains of R56, R127, and K49, and a hydrogen bond to the hydroxyl group of Y128 (Figs 2C and 2D). The proline residue in the phosphopeptide adopts a cis-conformation, producing a sharp change in chain direction and allowing the remaining portions of the peptide to exit the binding cleft (Yaffe et al. 1997, Rittinger et al. 1999).

The whole molecule of the 14-3-3 dimer is very rigid likely as a result of extensive interactions between helices. The most flexible region is the C-terminal segment which is also the most variable region among 14-3-3 isoforms. The highly conserved regions map to the interior surface of the central channel (Fig. 1B). The dimeric nature of $14-3-3$ proteins seems to be very important for their functions. Many binding partners of 14-3-3 proteins possess more than one 14-3-3 binding motif and the presence of two binding grooves within the 14-3-3 dimer might enable simultaneous binding of two phosphorylated motifs and thus more efficient ligand binding (Tzivion et al. 1998, Tzivion et al. 2000, Yaffe 2002, Shen et al. 2003). A synthetic peptide containing two 14-3-3 binding motifs binds with 30 times higher affinity compared to a peptide containing only one phosphorylated motif (Yaffe et al. 1997). Based on these observations a model for 14-3-3/ligand interaction has been proposed. This model suggests that 14-3-3 binding relies initially upon the interaction of a gatekeeper motif (a dominant binding motif) with one monomeric 14-3-3 subunit. This is followed by the binding of one or more weaker secondary sites to a second 14-3-3 subunit thus facilitating ligand conformation that is not favorable in the unbound state (e.g. exposing one or more regions of the protein that are inaccessible in the free or monomerbound form) (Yaffe 2002).

The function of 14-3-3 proteins can be generally classified on the basis of three modes of action (Bridges and Moorhead 2004): 


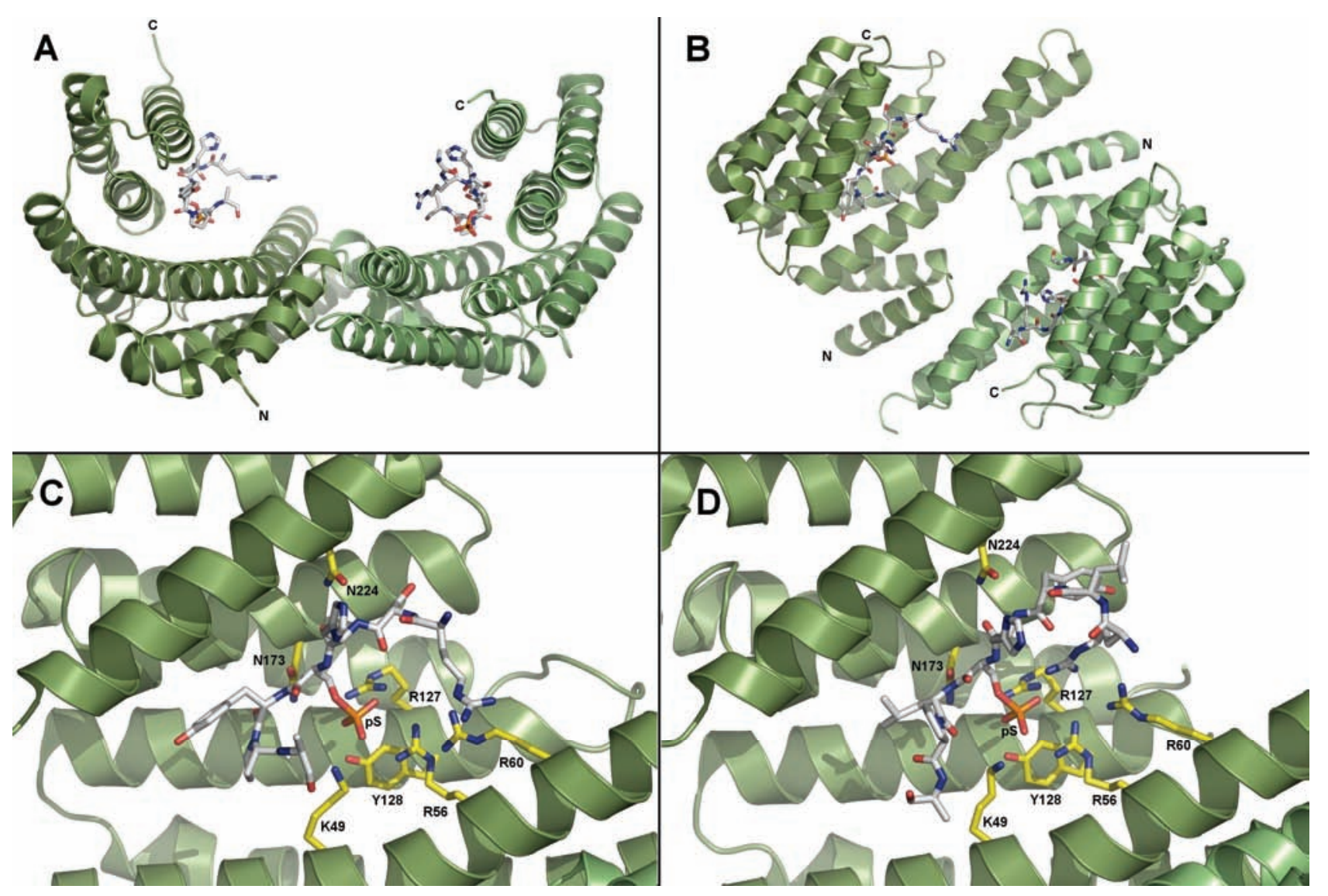

Fig. 2. Crystal structure of human 14-3-3ל isoform with bound phosphopeptides containing optimal 14-3-3 binding motif (Rittinger et al. 1999). (A and B) Two orthogonal views of $14-3-3 \zeta$ dimer (ribbon representation) with bound phosphopeptide (stick representation).

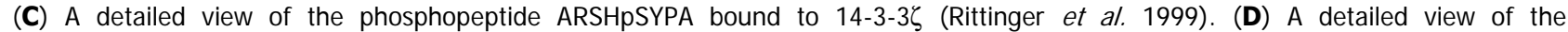
phosphopeptide RLYHPSLPA bound to 14-3-3ל (Rittinger et al. 1999).

(1) 14-3-3 protein changes conformation of its binding partner. The 14-3-3 dimer is a very rigid molecule thus it could serve as a base on which the target protein can be reshaped. If the binding partner is an enzyme, this can affect the enzymatic properties of the binding partner. An example of this mode of regulation is the 14-3-3 protein-dependent activation of serotonin $\mathrm{N}$-acetyltransferase (AANAT) (Ganguly et al. 2001, Obsil et al. 2001). This enzyme is in its free form catalytically inefficient mainly due to the low affinity for its substrates. Serotonin $K_{M}$ of free AANAT is $\sim 170 \mu \mathrm{M}$ while the cytoplasmic concentration of serotonin in the nighttime ovine pineal gland is $\sim 1 \mu \mathrm{M}$ (Ganguly et al. 2001). However, upon the phosphorylation the 14-3-3 protein binds to and stabilizes a region of AANAT molecule involved in substrate binding (Obsil et al. 2001). This structural stabilization increases the substrate affinity 10 -fold and activates the enzyme.

(2) 14-3-3 protein physically occludes sequencespecific or structural features of its binding partner. The 14-3-3 binding can also mask important features of the surface of the target protein. For example, several well characterized binding partners (e.g. FOXO transcription factors, protein phosphatase $\mathrm{Cdc} 25 \mathrm{C}$, histone deacetylases) contain a nuclear localization sequence (NLS) in close proximity of a 14-3-3 binding motif (Muslin and Xing 2000, Graves et al. 2001, Kao et al. 2001, Giles et al. 2003, Van Der Heide et al. 2004). It has therefore been suggested that the 14-3-3 protein binding inhibits the interaction between NLS and nuclear import machinery thus blocking nuclear localization of these proteins.

(3) 14-3-3 protein functions as a scaffold molecule to anchor proteins within close proximity of one another. Third possible function of 14-3-3 proteins is to act as scaffold molecule that stimulates protein-protein interactions. One monomer of the 14-3-3 dimer binds to a first protein and the other subunit binds to the second protein. Examples of this mode of action are 14-3-3mediated interactions between Tau and glycogen synthase kinase $3 \beta$ (Agarwal-Mawal et al. 2003), or the Ron receptor tyrosine kinase and $6 \beta 4 / 3 \beta 1$ integrin (Santoro et al. 2003). 


\section{Regulation of 14-3-3 proteins}

Most of the 14-3-3 protein isoforms, with the exception of mammalian $\sigma$ isoform, are ubiquitously expressed in all tissues and they bind their targets with similar affinity. Therefore the binding properties of 14-3-3 proteins seem to be regulated through post-translational modifications and/or the binding of cofactors (Athwal et al. 1998, Wurtele et al. 2003, Bridges and Moorhead 2004, Aitken 2006). From various post-translational modifications the phosphorylation of 14-3-3 isoforms on specific residues is now well established mechanism of 143-3 regulation (Mackintosh 2004, Aitken 2006). Phosphorylation sites are not conserved among 14-3-3 isoforms thus this post-translational modification can enable selective isoform regulation. 14-3-3 protein isoforms are phosphoryted at four sites by a number of Ser/Thr kinases that are known to be involved in cell signaling and regulation (Mackintosh 2004, Wilker and Yaffe 2004, Aitken 2006). Two sites are located at the

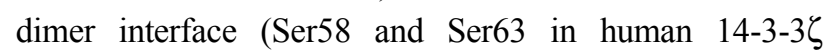
numbering) and it has been shown that phosphorylation of Ser58 promotes the formation of 14-3-3 monomers (Powell et al. 2003, Woodcock et al. 2003). Monomerization of otherwise dimeric 14-3-3 proteins might have profound effect on their function. The other two sites (Ser184 and Ser/Thr232) are located in the vicinity of the ligand binding groove and phosphorylation of both these sites have been shown to reduce ligand binding (Dubois et al. 1997, Aitken et al. 2002, Dumaz and Marais 2003, Obsilova et al. 2004, Tsuruta et al. 2004).

Phosphorylation site Ser/Thr232 is located within the C-terminal segment, a region that is believed to be flexible. The structure of this part of 14-3-3 molecule is unknown because it cannot be seen in any of the available 14-3-3 crystal structures presumably due to disorder (Liu et al. 1995, Xiao et al. 1995, Yaffe et al. 1997, Rittinger et al. 1999, Obsil et al. 2001). Several reports indicated that the C-terminal segment is involved in the regulation of ligand binding (Liu et al. 1995, Liu et al. 1996, Truong et al. 2002). Phosphorylation site Ser/Thr232 is present in the Cterminal segment of vertebrate $\zeta$ and $\tau$ isoforms only and can be phosphorylated both in vitro and in vivo by casein kinase I $\alpha$ (Dubois et al. 1997). It has also been shown that in human embryonic kidney 293 cells $14-3-3 \zeta$ is phosphorylated exclusively at Thr232 (Dubois et al. 1997). Since in these cells only non-phosphorylated $14-3-3 \zeta$ is bound to Raf-1 kinase (Rommel et al. 1996), it has been concluded that in vivo phosphorylation at Thr232 inhibits interaction between 14-3-3 $\zeta$ and Raf-1 kinase. Our group studied the conformational changes of $14-3-3 \zeta \mathrm{C}$ terminal stretch induced by phosphopeptide binding and phosphorylation at Thr232 (Obsilova et al. 2004, Silhan et al. 2004). Time-resolved fluorescence measurements revealed that the phosphopeptide binding changes the conformation and increases the flexibility of $14-3-3 \zeta \mathrm{C}$ terminal stretch, demonstrating that this region is directly involved in the ligand binding. The Förster resonance energy transfer (FRET) measurements between Trp residue inserted into the C-terminal segment and a dansyl group (attached at two different cysteine residues) indicated that, in the absence of the ligand, the C-terminal segment occupies the ligand binding groove of the 14-3-3 protein. Upon the phosphopeptide binding the C-terminal segment is displaced from the ligand binding groove and its flexibility increases. Phosphorylation of $14-3-3 \zeta$ at $\mathrm{Thr} 232$ changed the structure of the C-terminal segment and resulted in inhibition of phosphopeptide binding (Obsilova et al. 2004, Silhan et al. 2004). The precise mechanism of this inhibition is still unknown, but it is possible to speculate that phosphorylation-induced conformational change could affect interactions between the C-terminal segment and the ligand binding groove thus making its displacement from the groove more difficult.

The interaction between the 14-3-3 protein and its target can also be regulated by the presence of small molecule ligands. One of the best studied examples is fusicoccin, a terpenoid secreted by a fungal plant pathogen Fusicoccum amygdali. Fusicoccin specifically enhances the 14-3-3 protein binding to the plant plasma membrane $\mathrm{H}^{+}$-ATPase by stabilizing the interaction between the C-terminus of the $\mathrm{H}^{+}$-ATPase and 14-3-3 ligand binding groove (Wurtele et al. 2003). The crystal structure of the ternary complex between a plant 14-3-3 protein, fusicoccin and a phosphopeptide derived from the C-terminus of the $\mathrm{H}^{+}$-ATPase revealed that the compound fills a cavity in the protein-phosphopeptide interaction surface. Calorimetric measurements showed that the toxin alone binds only weakly to 14-3-3 and that peptide and toxin mutually increase each others' binding afinity $\sim 90$-fold (Wurtele et al. 2003).

\section{Role of 14-3-3 proteins in the regulation of FOXO forkhead transcription factors}

The forkhead box (FOX) transcription factors contain an approximately 110 amino acid long winged 


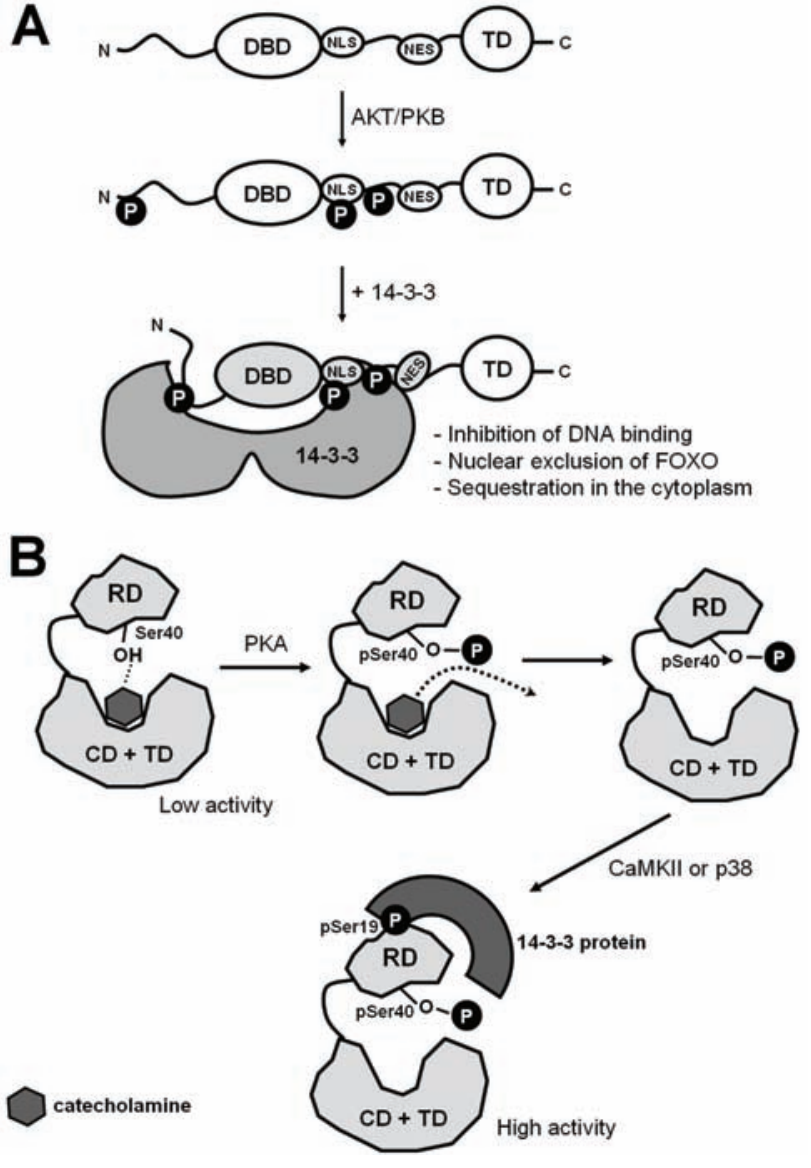

Fig. 3. (A) Schematic representation of primary structure of FOXO proteins. All FOXO proteins have the same domain organization and contain forkhead DNA binding domain (DBD), nuclear localization signal (NLS), nuclear export sequence (NES) and transactivation domain (TD). The AKT/PKB phosphorylation sites are labeled by black circles. (B) Diagram of tyrosine hydroxylase domain structure. Tyrosine hydroxylase contains three domains: regulatory domain (RD), catalytic domain (CD) and tetramerization domain (TD). It seems that the hydroxyl group of Ser40 stabilizes the catecholamine-bound inhibited form of TH (Ramsey and Fitzpatrick 1998). Phosphorylation of Ser40 induces a conformational change of the regulatory domain thus permitting easier dissociation of catecholamine and activation of TH (Wu et al. 1992, Bevilaqua et al. 2001, McCulloch et al. 2001). Phosphorylation of Ser19 induces TH binding to the 14-33 protein. That leads to the enhancement of the TH activity probably through the conformational change of regulatory domain (Obsilova et al. 2008).

helix DNA binding domain (DBD) known as the forkhead domain (Weigel and Jackle 1990, Kaestner et al. 2000). The FOX proteins display large functional diversity and play a wide range of roles in development, proliferation, differentiation, stress resistance, apoptosis and control of metabolism (Greer and Brunet 2005, van der Horst and Burgering 2007). Among the forkhead box family of transcription factors the "O" subgroup consists of four members (FOXO1, FOXO3, FOXO4, and FOXO6). They are the vertebrate orthologs of the Caenorhabditis elegans
DAF-16 transcription factor and constitute key components of a highly conserved signaling pathway that connects growth and stress signals to transcriptional control (Lin et al. 1997, Ogg et al. 1997).

Transcriptional activity of FOXO proteins is regulated through insulin-phosphatidylinositol 3-kinase protein kinase $\mathrm{B}$ (PI3K-AKT/PKB) signaling pathway. In response to growth signals, the PI3K activates AKT/PKB and related SGK (serum and glucocorticoid inducible kinase) that then phosphorylate FOXO proteins at three sites (Biggs et al. 1999, Kops et al. 1999, Brownawell et al. 2001) (Fig. 3A). Phosphorylation by AKT/PKB induces phosphorylation of additional sites by casein kinase 1 (CK1) and dual-specificity tyrosine-regulated kinase 1A (DIRK1). The AKT/PKB phosphorylates substrates that carry an $\operatorname{RXRXX}(\mathrm{S} / \mathrm{T})$ motif, which is close to the consensus 14-3-3 binding motifs (Alessi et al. 1996, Yaffe et al. 1997, Rittinger et al. 1999). The AKT/PKB-dependent phosphorylation of sites at the $\mathrm{N}$-terminus and in the forkhead domain of FOXO proteins creates two 14-3-3 binding motifs and induces FOXO binding to nuclear 14-3-3 proteins (Brunet et al. 1999, Brunet et al. 2002). It has been shown that simultaneous use of both AKT/14-3-3 motifs is necessary for optimal FOXO binding to 14-3-3 proteins (Brunet et al. 1999, Brunet et al. 2002, Obsil et al. 2003, Zhao et al. 2004). These two motifs border the DNA binding domain, raising the possibility that 14-3-3 proteins could participate in disruption of FOXO binding to the DNA. Such 14-3-3 protein-dependent inhibition of DNA binding has been observed for DAF-16 and FOXO4 (Cahill et al. 2001, Obsil et al. 2003, Boura et al. 2007). However, the exact mechanism of this 14-3-3-dependent inhibition of DNA binding is still unclear. Since the second AKT/PKB motif is embedded in the C-terminal part of forkhead domain, the 14-3-3 protein could affect the binding of this region to the DNA, mask other parts of FOXO DNA binding interface, or change the conformation of forkhead domain.

The association of FOXO factors with 14-3-3 proteins has another important consequence. Upon the 143-3 protein binding the resulting FOXO-14-3-3 complexes are rapidly transported out of the nucleus and retained within the cytoplasm (Biggs et al. 1999, Brunet et al. 1999, Nakae et al. 1999, Brunet et al. 2002). The exact mechanism of this process is unknown but 14-3-3 proteins have been shown to bind to phosphorylated FOXO in the nucleus where, along with the inhibition of DNA binding, could induce a conformational change in FOXO molecules 
and expose their NES for interaction with Exportin/Crm1 (Brunet et al. 2002). In addition, all FOXO proteins contain a sequence that represents a nonclassical bipartite NLS. In general, nuclear localization signals do not conform to a specific consensus sequence but form two distinct classes termed monopartite NLS, consisting of a single cluster of basic amino acid residues, and bipartite NLS, consisting of two basic clusters separated by a variable spacer. These two basic clusters are independent and usually are both required for nuclear targeting (Dingwall and Laskey 1991). NLS found in FOXO proteins consists of two clusters containing in total 12 arginine and lysine residues positioned on both sides of the second AKT/14-3-3 binding motif in the C-terminus of forkhead domain. Therefore, it has been suggested that 143-3 proteins may prevent nuclear reimport of FOXO proteins by masking their NLS (Brunet et al. 1999, Brownawell et al. 2001, Rena et al. 2001) (Fig. 3A). To provide experimental evidence showing a direct interaction between the 14-3-3 protein and NLS of FOXO our group investigated whether the 14-3-3 protein binding affects the structure of FOXO4 NLS by means of fluorescence spectroscopy. We showed that the 14-3-3 protein binding significantly changes the environment around AEDANSlabeled NLS and reduces its flexibility. On the other hand, the phosphorylation itself and the binding of doublestranded DNA have a small effect on the structure of this region. Crystal structures of various 14-3-3 protein complexes showed that the 14-3-3 ligand-binding groove can accommodate a polypeptide chain about 9 amino acid residues long with the $\mathrm{pS}$ or $\mathrm{pT}$ in the middle (Yaffe et al. 1997, Rittinger et al. 1999, Obsil et al. 2001). Therefore, the first part of FOXO4 bipartite NLS (three arginine residues located upstream to the second $\mathrm{AKT} / \mathrm{PKB}$ site) would likely be directly buried within the ligand-binding groove upon the 14-3-3 protein binding. However, the second part of FOXO4 NLS consisting of 7 basic residues located between Lys199 and Lys211 is far enough from the second AKT/PKB motif to be buried within the 14-3-3 ligand-binding groove. Significant reduction of fast segmental movements of AEDANS-labeled NLS together with changes in the polarity of the microenvironment around this group indicated that the second part of FOXO4 NLS either directly interacts with the 14-3-3 protein or dramatically changes its conformation as a result of complex formation. Therefore we concluded that the binding of the 14-3-3 protein can affect the whole region of FOXO4 NLS (Obsilova et al. 2005).

In addition to AKT/PKB-mediated phosphory- lation, the function of FOXO proteins is also controlled by other types of post-translational modifications including non-AKT/PKB-mediated phosphorylation, acetylation, and ubiquitination (van der Horst and Burgering 2007). The mechanisms by which posttranslational modifications regulate FOXO functions are mostly elusive, but in many cases they seem to affect DNA binding potential of FOXO proteins, function of their nuclear localization signal (NLS) and nuclear export sequence (NES), or interactions of FOXO with other proteins.

\section{Role of 14-3-3 proteins in the regulation of tyrosine hydroxylase}

Tyrosine hydroxylase (TH, EC 1.14.16.2) catalyzes the first step in the biosynthesis of catecholamines and its activity is controlled by multiple mechanisms including feedback inhibition by catecholamines, allosteric activation by heparin, phospholipids, and RNA, and activation by protein phosphorylation (Nagatsu et al. 1964, Fitzpatrick 1999). N-terminal regulatory domain of TH consists of 160-190 amino acid residues (in human isoforms) and can be removed without a significant decrease in catalytic activity (Daubner et al. 1993). Regulatory domain can be phosphorylated at four serine residues Ser8, Ser19, Ser31, and Ser40 in vitro, in situ and in vivo (Haycock 1990, Haycock and Haycock 1991, Fitzpatrick 1999). Among these, the effects of Ser19 and Ser40 phosphorylation are the best characterized. Residue Ser40 can be phosphorylated by a number of protein kinases and its phosphorylation by cyclic AMP-dependent protein kinase (PKA) induces the most potent activation of $\mathrm{TH}$ (Daubner et al. 1992, Ramsey and Fitzpatrick 1998). It has been proposed that phosphorylation of Ser40 alters conformation of the regulatory domain and its interaction with the catalytic domain. Phosphorylation of Ser40 is known to increase the sensitivity to proteolysis in its surrounding, while dopamine binding has the opposite effect, suggesting that there is a link between the conformation of the regulatory domain and the enzyme activity (McCulloch and Fitzpatrick 1999). It has been proposed that the hydroxyl group of Ser40 contributes to the stabilization of the catecholamine-bound inhibited form of TH (Ramsey and Fitzpatrick 1998). Phosphorylation of Ser40 probably induces a conformational change of the regulatory domain thus permitting easier dissociation of catecholamine and 
activation of TH (Wu et al. 1992, Bevilaqua et al. 2001, McCulloch et al. 2001). In contrast to phosphorylation at Ser40, the activation of TH through the phosphorylation of Ser19 requires the presence of regulatory 14-3-3 protein (Yamauchi and Fujisawa 1981, Ichimura et al. 1987, Itagaki et al. 1999) (Fig. 3B).

Regulatory domain of TH contains two 14-3-3 protein binding motifs around residues Ser19 and Ser40. Detailed analysis of interactions between $\mathrm{TH}$ and different 14-3-3 protein isoforms using surface plasmon resonance confirmed that phosphorylation of Ser19 is required for stable association of human $\mathrm{TH}$ isoforms with bovine 14-3-3 $\zeta$ isoform (Kleppe et al. 2001). On the other hand, Kleppe et al. (2001) also showed that yeast 14-3-3 protein isoform (BMH1) can bind with high affinity to all four human $\mathrm{TH}$ isoforms phosphorylated only at Ser40. The reason why yeast but not mammalian 14-3-3 protein isoforms bind to TH phosphorylated only at Ser40 is unknown.

The role of 14-3-3 protein in the regulation of TH activity is still unclear. While one study found that 14-3-3 protein binding to $\mathrm{TH}$ phosphorylated at Ser19 increased $\mathrm{V}_{\max }$ threefold (Toska et al. 2002), other studies observed no 14-3-3-dependent enhancement of TH activity (Haycock and Wakade 1992, Sutherland et al. 1993). It has also been suggested that 14-3-3 protein might protect proteolytically very sensitive phosphorylated regulatory domain of $\mathrm{TH}$, and/or slowdown dephosphorylation of phosphorylated Ser19 and Ser40 (Kleppe et al. 2001, Toska et al. 2002). Phosphorylation status of regulatory domain seems to be important for overall stability of TH because it has been shown that multiphosphorylated form of $\mathrm{TH}$ is more stable than the single and unphosphorylated forms, regardless of phosphorylation sites (Bevilaqua et al. 2001, Toska et al. 2002, Royo et al. 2005). Since 14-3-3 proteins are known to modulate the structure of their binding partners (Obsil et al. 2001, Yaffe 2002, Obsilova et al. 2005), it is reasonable to speculate that 14-3-3 protein changes the structure of phosphorylated regulatory domain of $\mathrm{TH}$, thus making it less sensitive to proteolysis and/or dephosphorylation (Fig. 3B). To test this hypothesis we recently investigated whether the 14-3-3 $\zeta$ protein binding affects conformation of the regulatory domain of human TH isoform 1 (denoted as TH1R) phosphorylated at both Ser19 and Ser40 (Obsilova et al. 2008). Site-directed mutagenesis was used to generate five single tryptophan mutants with tryptophan residue located at different positions within the regulatory domain (positions 14, 34, 73, 103, and 131). Time-resolved tryptophan fluorescence intensity decays revealed that phosphorylation of Ser 19 and Ser40 by itself does not induce significant conformational changes in the regions surrounding inserted tryptophans. However, the binding of the $14-3-3 \zeta$ protein induces distinct structural changes in the $\mathrm{N}$-terminal part of doubly phosphorylated regulatory domain. In addition, tryptophan fluorescence quenching experiments with acrylamide revealed that $14-3-3 \zeta$ protein binding decreases the exposure of tryptophan residues at positions 14 and 34. The 14-3-3 $\zeta$ protein binding also reduces the sensitivity of regulatory domain to proteolysis by protecting the cleavage site between residues 33 and 34 . Circular dichroism measurements showed that regulatory domain of TH isoform 1 is an unstructured protein with low content of secondary structure and that neither phosphorylation nor the $14-3-3 \zeta$ protein binding change its secondary structure. These results are consistent with the hypothesis that the 14-3-3 protein affects the structure of phosphorylated regulatory domain of $\mathrm{TH}$, thus increasing its stability and helping to keep $\mathrm{TH}$ in the activated state .

\section{Conclusions}

The 14-3-3 isoforms play various roles in the regulation of many cellular proteins. While they activate or stabilize some proteins, and inactivate others, for many proteins 14-3-3 isoforms play an organizational role as a "scaffold" molecules. Through the functional modulation of a wide range of targets, 14-3-3 isoforms are involved in many processes, including cell cycle regulation, metabolism control, apoptosis, and control of gene transcription. Due to the multitude of 14-3-3 binding partners and physiological activities, a specific definition of their cellular role or function is difficult. Recent studies have made great progress towards elucidating the functions of 14-3-3 proteins and proteomic approaches has allowed us to better understand the interactions of 14-3-3 with other proteins. However, much yet remains to be discovered. The mechanisms of 14-3-3 protein action are now known to be complex and their better understanding will require the crystal structure of additional 14-3-3-targets, both free and in complex with 14-3-3 proteins.

\section{Conflict of Interest}

There is no conflict of interest. 


\section{Acknowledgements}

The authors are supported by the Grant Agency of the Czech Republic (projects 204/06/0565 and GD203/05/H001), the Grant Agency of the Academy of Sciences of the Czech Republic (projects IAA501110801 and KJB500110601), the Ministry of Education, Youth, and Sports of the Czech Republic (MSM0021620857, LC554) and the Academy of Sciences of the Czech Republic (AV0Z50110509).

\section{References}

AGARWAL-MAWAL A, QURESHI HY, CAFFERTY PW, YUAN Z, HAN D, LIN R, PAUDEL HK: 14-3-3 connects glycogen synthase kinase-3 beta to tau within a brain microtubule-associated tau phosphorylation complex. J Biol Chem 278: 12722-12728, 2003.

AITKEN A: 14-3-3 proteins: a historic overview. Semin Cancer Biol 16: 162-172, 2006.

AITKEN A, BAXTER H, DUBOIS T, CLOKIE S, MACKIE S, MITCHELL K, PEDEN A, ZEMLICKOVA E: Specificity of 14-3-3 isoform dimer interactions and phosphorylation. Biochem Soc Trans 30: 351-360, 2002.

ALESSI DR, CAUDWELL FB, ANDJELKOVIC M, HEMMINGS BA, COHEN P: Molecular basis for the substrate specificity of protein kinase B; comparison with MAPKAP kinase-1 and p70 S6 kinase. FEBS Lett 399: 333338, 1996.

ATHWAL GS, HUBER JL, HUBER SC: Biological significance of divalent metal ion binding to 14-3-3 proteins in relationship to nitrate reductase inactivation. Plant Cell Physiol 39: 1065-1072, 1998.

BEVILAQUA LR, GRAHAM ME, DUNKLEY PR, VON NAGY-FELSOBUKI EI, DICKSON PW: Phosphorylation of Ser(19) alters the conformation of tyrosine hydroxylase to increase the rate of phosphorylation of Ser(40). $J$ Biol Chem 276: 40411-40416, 2001.

BIGGS WH, 3RD, MEISENHELDER J, HUNTER T, CAVENEE WK, ARDEN KC: Protein kinase B/Akt-mediated phosphorylation promotes nuclear exclusion of the winged helix transcription factor FKHR1. Proc Natl Acad Sci U S A 96: 7421-7426, 1999.

BOURA E, SILHAN J, HERMAN P, VECER J, SULC M, TEISINGER J, OBSILOVA V, OBSIL T: Both the Nterminal loop and wing W2 of the forkhead domain of transcription factor FoxO4 are important for DNA binding. J Biol Chem 282: 8265-8275, 2007.

BRIDGES D, MOORHEAD GB: 14-3-3 proteins: a number of functions for a numbered protein. SCi STKE 2004: re10, 2004.

BROWNAWELL AM, KOPS GJ, MACARA IG, BURGERING BM: Inhibition of nuclear import by protein kinase B (Akt) regulates the subcellular distribution and activity of the forkhead transcription factor AFX. Mol Cell Biol 21: 3534-3546, 2001.

BRUNET A, BONNI A, ZIGMOND MJ, LIN MZ, JUO P, HU LS, ANDERSON MJ, ARDEN KC, BLENIS J, GREENBERG ME: Akt promotes cell survival by phosphorylating and inhibiting a Forkhead transcription factor. Cell 96: 857-868, 1999.

BRUNET A, KANAI F, STEHN J, XU J, SARBASSOVA D, FRANGIONI JV, DALAL SN, DECAPRIO JA, GREENBERG ME, YAFFE MB: 14-3-3 transits to the nucleus and participates in dynamic nucleocytoplasmic transport. J Cell Biol 156: 817-828, 2002.

CAHILL CM, TZIVION G, NASRIN N, OGG S, DORE J, RUVKUN G, ALEXANDER-BRIDGES M: Phosphatidylinositol 3-kinase signaling inhibits DAF-16 DNA binding and function via 14-3-3-dependent and 14-3-3-independent pathways. J Biol Chem 276: 13402-13410, 2001.

DAUBNER SC, LAURIANO C, HAYCOCK JW, FITZPATRICK PF: Site-directed mutagenesis of serine 40 of rat tyrosine hydroxylase. Effects of dopamine and cAMP-dependent phosphorylation on enzyme activity. $J$ Biol Chem 267: 12639-12646, 1992.

DAUBNER SC, LOHSE DL, FITZPATRICK PF: Expression and characterization of catalytic and regulatory domains of rat tyrosine hydroxylase. Protein Sci 2: 1452-1460, 1993.

DINGWALL C, LASKEY RA: Nuclear targeting sequences--a consensus? Trends Biochem Sci 16: 478-481, 1991. 
DUBOIS T, ROMMEL C, HOWELL S, STEINHUSSEN U, SONEJI Y, MORRICE N, MOELLING K, AITKEN A: 14-3-3 is phosphorylated by casein kinase I on residue 233. Phosphorylation at this site in vivo regulates Raf/14-3-3 interaction. J Biol Chem 272: 28882-28888, 1997.

DUMAZ N, MARAIS R: Protein kinase A blocks Raf-1 activity by stimulating 14-3-3 binding and blocking Raf-1 interaction with Ras. J Biol Chem 278: 29819-29823, 2003.

FITZPATRICK PF: Tetrahydropterin-dependent amino acid hydroxylases. Annu Rev Biochem 68: 355-381, 1999.

FU H, SUBRAMANIAN RR, MASTERS SC: 14-3-3 proteins: structure, function, and regulation. Annu Rev Pharmacol Toxicol 40: 617-647, 2000.

GANGULY S, GASTEL JA, WELLER JL, SCHWARTZ C, JAFFE H, NAMBOODIRI MA, COON SL, HICKMAN AB, ROLLAG M, OBSIL T, BEAUVERGER P, FERRY G, BOUTIN JA, KLEIN DC: Role of a pineal cAMP-operated arylalkylamine N-acetyltransferase/14-3-3-binding switch in melatonin synthesis. Proc Natl Acad Sci U S A 98: 8083-8088, 2001.

GILES N, FORREST A, GABRIELLI B: 14-3-3 acts as an intramolecular bridge to regulate cdc25B localization and activity. J Biol Chem 278: 28580-28587, 2003.

GRAVES PR, LOVLY CM, UY GL, PIWNICA-WORMS H: Localization of human Cdc25C is regulated both by nuclear export and 14-3-3 protein binding. Oncogene 20: 1839-1851, 2001.

GREER EL, BRUNET A: FOXO transcription factors at the interface between longevity and tumor suppression. Oncogene 24: 7410-7425, 2005.

HAYCOCK JW: Phosphorylation of tyrosine hydroxylase in situ at serine 8, 19, 31, and 40. J Biol Chem 265: $11682-$ $11691,1990$.

HAYCOCK JW, HAYCOCK DA: Tyrosine hydroxylase in rat brain dopaminergic nerve terminals. Multiple-site phosphorylation in vivo and in synaptosomes. $J$ Biol Chem 266: 5650-5657, 1991.

HAYCOCK JW, WAKADE AR: Activation and multiple-site phosphorylation of tyrosine hydroxylase in perfused rat adrenal glands. $J$ Neurochem 58: 57-64, 1992.

HERMEKING H, BENZINGER A: 14-3-3 proteins in cell cycle regulation. Semin Cancer Biol 16: 183-192, 2006.

ICHIMURA T, ISOBE T, OKUYAMA T, YAMAUCHI T, FUJISAWA H: Brain 14-3-3 protein is an activator protein that activates tryptophan 5-monooxygenase and tyrosine 3-monooxygenase in the presence of $\mathrm{Ca}^{2+}$,calmodulin-dependent protein kinase II. FEBS Lett 219: 79-82, 1987.

ITAGAKI C, ISOBE T, TAOKA M, NATSUME T, NOMURA N, HORIGOME T, OMATA S, ICHINOSE H, NAGATSU T, GREENE LA, ICHIMURA T: Stimulus-coupled interaction of tyrosine hydroxylase with 14-33 proteins. Biochemistry 38: 15673-15680, 1999.

KAESTNER KH, KNOCHEL W, MARTINEZ DE: Unified nomenclature for the winged helix/forkhead transcription factors. Genes Dev 14: 142-146, 2000.

KAO HY, VERDEL A, TSAI CC, SIMON C, JUGUILON H, KHOCHBIN S: Mechanism for nucleocytoplasmic shuttling of histone deacetylase 7. J Biol Chem 276: 47496-47507, 2001.

KLEPPE R, TOSKA K, HAAVIK J: Interaction of phosphorylated tyrosine hydroxylase with 14-3-3 proteins: evidence for a phosphoserine 40-dependent association. J Neurochem 77: 1097-1107, 2001.

KOPS GJ, DE RUITER ND, DE VRIES-SMITS AM, POWELL DR, BOS JL, BURGERING BM: Direct control of the Forkhead transcription factor AFX by protein kinase B. Nature 398: 630-634, 1999.

LIN K, DORMAN JB, RODAN A, KENYON C: daf-16: an HNF-3/forkhead family member that can function to double the life-span of Caenorhabditis elegans. Science 278: 1319-1322, 1997.

LIU D, BIENKOWSKA J, PETOSA C, COLLIER RJ, FU H, LIDDINGTON R: Crystal structure of the zeta isoform of the 14-3-3 protein. Nature 376: 191-194, 1995.

LIU YC, ELLY C, YOSHIDA H, BONNEFOY-BERARD N, ALTMAN A: Activation-modulated association of 14-33 proteins with Cbl in T cells. $J$ Biol Chem 271: 14591-14595, 1996.

MACKINTOSH C: Dynamic interactions between 14-3-3 proteins and phosphoproteins regulate diverse cellular processes. Biochem J 381: 329-342, 2004.

MCCULLOCH RI, DAUBNER SC, FITZPATRICK PF: Effects of substitution at serine 40 of tyrosine hydroxylase on catecholamine binding. Biochemistry 40: 7273-7278, 2001. 
MCCULLOCH RI, FITZPATRICK PF: Limited proteolysis of tyrosine hydroxylase identifies residues 33-50 as conformationally sensitive to phosphorylation state and dopamine binding. Arch Biochem Biophys 367: 143$145,1999$.

MOORE BW, PEREZ VJ: Specific acid proteins in the nervous system. In: Physiological and Biochemical Aspects of Nervous Integration. FD CARLSON (ed), Prentice Hall, New Jersey, Englewood Cliffs, 1967, pp 343-359.

MUSLIN AJ, TANNER JW, ALLEN PM, SHAW AS: Interaction of 14-3-3 with signaling proteins is mediated by the recognition of phosphoserine. Cell 84: 889-897, 1996.

MUSLIN AJ, XING H: 14-3-3 proteins: regulation of subcellular localization by molecular interference. Cell Signal 12: 703-709, 2000.

NAGATSU T, LEVITT M, UDENFRIEND S: Tyrosine hydroxylase. the initial step in norepinephrine biosynthesis. $J$ Biol Chem 239: 2910-2917, 1964.

NAKAE J, PARK BC, ACCILI D: Insulin stimulates phosphorylation of the forkhead transcription factor FKHR on serine 253 through a wortmannin-sensitive pathway. J Biol Chem 274: 15982-15985, 1999.

OBSIL T, GHIRLANDO R, ANDERSON DE, HICKMAN AB, DYDA F: Two 14-3-3 binding motifs are required for stable association of Forkhead transcription factor FOXO4 with 14-3-3 proteins and inhibition of DNA binding. Biochemistry 42: 15264-15272, 2003.

OBSIL T, GHIRLANDO R, KLEIN DC, GANGULY S, DYDA F: Crystal structure of the 14-3-3zeta:serotonin Nacetyltransferase complex. a role for scaffolding in enzyme regulation. Cell 105: 257-267, 2001.

OBSILOVA V, HERMAN P, VECER J, SULC M, TEISINGER J, OBSIL T: 14-3-3zeta C-terminal stretch changes its conformation upon ligand binding and phosphorylation at Thr232. J Biol Chem 279: 4531-4540, 2004.

OBSILOVA V, NEDBALKOVA E, SILHAN J, BOURA E, HERMAN P, VECER J, SULC M, TEISINGER J, DYDA F, OBSIL T: The 14-3-3 protein affects the conformation of the regulatory domain of human tyrosine hydroxylase. Biochemistry 47: 1768-1777, 2008.

OBSILOVA V, VECER J, HERMAN P, PABIANOVA A, SULC M, TEISINGER J, BOURA E, OBSIL T: 14-3-3 Protein interacts with nuclear localization sequence of forkhead transcription factor FoxO4. Biochemistry 44: 11608-11617, 2005.

OGG S, PARADIS S, GOTTLIEB S, PATTERSON GI, LEE L, TISSENBAUM HA, RUVKUN G: The Fork head transcription factor DAF-16 transduces insulin-like metabolic and longevity signals in C. elegans. Nature 389: 994-999, 1997.

PETOSA C, MASTERS SC, BANKSTON LA, POHL J, WANG B, FU H, LIDDINGTON RC: 14-3-3zeta binds a phosphorylated Raf peptide and an unphosphorylated peptide via its conserved amphipathic groove. $J$ Biol Chem 273: 16305-16310, 1998.

POWELL DW, RANE MJ, JOUGHIN BA, KALMUKOVA R, HONG JH, TIDOR B, DEAN WL, PIERCE WM, KLEIN JB, YAFFE MB, MCLEISH KR: Proteomic identification of 14-3-3zeta as a mitogen-activated protein kinase-activated protein kinase 2 substrate: role in dimer formation and ligand binding. Mol Cell Biol 23: 5376-5387, 2003.

RAMSEY AJ, FITZPATRICK PF: Effects of phosphorylation of serine 40 of tyrosine hydroxylase on binding of catecholamines: evidence for a novel regulatory mechanism. Biochemistry 37: 8980-8986, 1998.

RENA G, PRESCOTT AR, GUO S, COHEN P, UNTERMAN TG: Roles of the forkhead in rhabdomyosarcoma (FKHR) phosphorylation sites in regulating 14-3-3 binding, transactivation and nuclear targetting. Biochem J 354: 605-612, 2001.

RITTINGER K, BUDMAN J, XU J, VOLINIA S, CANTLEY LC, SMERDON SJ, GAMBLIN SJ, YAFFE MB: Structural analysis of 14-3-3 phosphopeptide complexes identifies a dual role for the nuclear export signal of 14-3-3 in ligand binding. Mol Cell 4: 153-166, 1999.

ROMMEL C, RADZIWILL G, LOVRIC J, NOELDEKE J, HEINICKE T, JONES D, AITKEN A, MOELLING K: Activated Ras displaces 14-3-3 protein from the amino terminus of c-Raf-1. Oncogene 12: 609-619, 1996.

ROYO M, FITZPATRICK PF, DAUBNER SC: Mutation of regulatory serines of rat tyrosine hydroxylase to glutamate: effects on enzyme stability and activity. Arch Biochem Biophys 434: 266-274, 2005.

SANTORO MM, GAUDINO G, MARCHISIO PC: The MSP receptor regulates alpha6beta4 and alpha3beta1 integrins via 14-3-3 proteins in keratinocyte migration. Dev Cell 5: 257-271, 2003. 
SHEN YH, GODLEWSKI J, BRONISZ A, ZHU J, COMB MJ, AVRUCH J, TZIVION G: Significance of 14-3-3 selfdimerization for phosphorylation-dependent target binding. Mol Biol Cell 14: 4721-4733, 2003.

SILHAN J, OBSILOVA V, VECER J, HERMAN P, SULC M, TEISINGER J, OBSIL T: 14-3-3 protein C-terminal stretch occupies ligand binding groove and is displaced by phosphopeptide binding. J Biol Chem 279: 4911349119, 2004.

SUTHERLAND C, ALTERIO J, CAMPBELL DG, LE BOURDELLES B, MALLET J, HAAVIK J, COHEN P: Phosphorylation and activation of human tyrosine hydroxylase in vitro by mitogen-activated protein (MAP) kinase and MAP-kinase-activated kinases 1 and 2. Eur J Biochem 217: 715-722, 1993.

TOSKA K, KLEPPE R, ARMSTRONG CG, MORRICE NA, COHEN P, HAAVIK J: Regulation of tyrosine hydroxylase by stress-activated protein kinases. J Neurochem 83: 775-783, 2002.

TRUONG AB, MASTERS SC, YANG H, FU H: Role of the 14-3-3 C-terminal loop in ligand interaction. Proteins 49: 321-325, 2002.

TSURUTA F, SUNAYAMA J, MORI Y, HATTORI S, SHIMIZU S, TSUJIMOTO Y, YOSHIOKA K, MASUYAMA N, GOTOH Y: JNK promotes Bax translocation to mitochondria through phosphorylation of 14-3-3 proteins. Embo J 23: 1889-1899, 2004.

TZIVION G, LUO Z, AVRUCH J: A dimeric 14-3-3 protein is an essential cofactor for Raf kinase activity. Nature 394: 88-92, 1998.

TZIVION G, LUO ZJ, AVRUCH J: Calyculin A-induced vimentin phosphorylation sequesters 14-3-3 and displaces other 14-3-3 partners in vivo. J Biol Chem 275: 29772-29778, 2000.

VAN DER HEIDE LP, HOEKMAN MF, SMIDT MP: The ins and outs of FoxO shuttling: mechanisms of FoxO translocation and transcriptional regulation. Biochem J 380: 297-309, 2004.

VAN DER HORST A, BURGERING BM: Stressing the role of FoxO proteins in lifespan and disease. Nat Rev Mol Cell Biol 8: 440-450, 2007.

WEIGEL D, JACKLE H: The fork head domain - a novel DNA-binding motif of eukaryotic transcription factors. Cell 63: 455-456, 1990.

WILKER E, YAFFE MB: 14-3-3 Proteins - a focus on cancer and human disease. J Mol Cell Cardiol 37: 633-642, 2004.

WILKER EW, GRANT RA, ARTIM SC, YAFFE MB: A structural basis for 14-3-3sigma functional specificity. $J$ Biol Chem 280: 18891-18898, 2005.

WOODCOCK JM, MURPHY J, STOMSKI FC, BERNDT MC, LOPEZ AF: The dimeric versus monomeric status of 14-3-3zeta is controlled by phosphorylation of Ser58 at the dimer interface. J Biol Chem 278: 36323-36327, 2003.

WU J, FILER D, FRIEDHOFF AJ, GOLDSTEIN M: Site-directed mutagenesis of tyrosine hydroxylase. Role of serine 40 in catalysis. $J$ Biol Chem 267: 25754-25758, 1992.

WURTELE M, JELICH-OTTMANN C, WITTINGHOFER A, OECKING C: Structural view of a fungal toxin acting on a 14-3-3 regulatory complex. EMBO J 22: 987-994, 2003.

XIAO B, SMERDON SJ, JONES DH, DODSON GG, SONEJI Y, AITKEN A, GAMBLIN SJ: Structure of a 14-3-3 protein and implications for coordination of multiple signalling pathways. Nature 376: 188-191, 1995.

YAFFE MB: How do 14-3-3 proteins work? Gatekeeper phosphorylation and the molecular anvil hypothesis. FEBS Lett 513: 53-57, 2002.

YAFFE MB, RITTINGER K, VOLINIA S, CARON PR, AITKEN A, LEFFERS H, GAMBLIN SJ, SMERDON SJ, CANTLEY LC: The structural basis for 14-3-3:phosphopeptide binding specificity. Cell 91: 961-971, 1997.

YAMAUCHI T, FUJISAWA H: Tyrosine 3-monoxygenase is phosphorylated by $\mathrm{Ca}^{2+}$-, calmodulin-dependent protein kinase, followed by activation by activator protein. Biochem Biophys Res Commun 100: 807-813, 1981.

ZHAO X, GAN L, PAN H, KAN D, MAJESKI M, ADAM SA, UNTERMAN TG: Multiple elements regulate nuclear/cytoplasmic shuttling of FOXO1: characterization of phosphorylation- and 14-3-3-dependent and independent mechanisms. Biochem J 378: 839-849, 2004. 